Revista Signos
$2010 / 43$

Número Especial

Monográfico $\mathrm{N}^{\circ} 1$

77-90

\author{
Patrick Charaudeau \\ Universidad de Paris XIII \\ Francia
}

\title{
Uma problemática comunicacional dos gêneros discursivos $^{1}$
}

Resumo: Podemos considerar, de forma simplificada, que a questão dos gêneros não literários foi, ou é, abordada de diversas maneiras: descrevendo as características formais dos textos; tentando definir os tipos de organização discursiva, tais como o 'narrativo', o 'argumentativo', o 'explicativo', o 'descritivo', etc.; determinando as 'situações de comunicação' que resultam da maneira como uma sociedade estrutura, institucionalmente, a prática social em grandes setores de atividade como o 'político', o 'religioso', o 'jurídico', o 'científico', o 'educativo', etc. Meu ponto de vista consiste em levantar a hipótese de que o ato de linguajem como toda prática social tende a regular as trocas verbais e a instaurar regularidades discursivas, como mostrou a etnometodologia com a descrição das ritualizações linguageiras, Ainda falta encontrar o meio de articular o domínio de prática social com a atividade discursiva. A dificuldade vem do fato que estes domínios de prática são extensivos demais e englobantes para que se possa marcar regularidades discursivas. A proposição que vai se seguir consiste precisamente em estruturar o domínio de prática social em domínio de comunicação.

Palavras-Chave: Discurso, gêneros discursivos, contrato de comunicação, gênero pagandístico, gênero publicitário, gênero político.

Recibido: 20-XI-2009 Aceptado: 24-V-2010
Correspondencia: Patrick Charaudeau (patrick.charaudeau@free.fr). Centre d'Analyse du Discours, Universidad de Paris XIII. 18, rue Rémy Dumoncel, 75014, Paris, Francia. 


\section{Una problemática comunicacional de los géneros discursivos}

Resumen: Consideramos, en forma simplificada, que la cuestión de los géneros no literarios era, o es, abordada de diversas maneras: mediante la descripción de las características formales de los textos; tratando de definir los tipos de organización del discurso, como el 'narrativo', el 'argumentativo', la 'exposición de motivos', el 'descriptivo', etc.; determinando las 'situaciones de comunicación' que surgen de la forma en que una sociedad estructura, institucionalmente, la práctica social de grandes sectores de la actividad como el 'político', el 'religioso', el 'legal', el 'científico', el 'educativo', etc. Mi punto de vista consiste en plantear la hipótesis de que el acto del lenguage como cualquier práctica social tiende a regular los cambios verbales y a establecer regularidades discursivas, como muestra la etnometodología con la descripción de las ritualizaciones lingüísticas. Todavía falta encontrar maneras de articular el campo de la práctica social con aquel de la actividad discursiva. La dificultad proviene en virtud de que estas áreas de la práctica son demasiado amplias y englobantes para que se puedan marcar regularidades discursivas. La propuesta consiste, precisamente, en estructurar el dominio de la práctica social en el dominio de la comunicación.

Palabras Clave: Discurso, géneros discursivos, contrato de comunicación, Género propagandístico, Género publicitario, Género político.

\section{A communicational problem arising from discursive genres}

Abstract: In simplified terms, the non-literary issues was, or is, addressed in different ways: through the description of the formal features of texts, attempting to define the types of organization of the discourse, such as the 'narrative', the 'argumentative', the 'exposition of motives', the 'descriptive', etc., thus determining the 'communicative situations' that emerge from the way in which a society institutionally articulates the social practice of its major activities, such as 'political', 'religious', 'legal', 'scientific', educational', etc. This paper presents a perspective based on the hypothesis that language acts, as any other social practices, tend to regulate verbal changes and to establish discursive regularities, as shown by descriptions of linguistic rituals provided ethnomethodology. Ways to articulate the social practice field with that of the discursive activity are yet to be found. Difficulties lie in both the broadness and inclusiveness of these practices, so they can mark discursive regularities. It is suggested, then, that structuring the social practice domain around the communication domain should be established.

Key Words: Discourse, discursive genres, communicative contract, propaganda genre, advertising genre, political genre. 


\section{INTRODUÇÃO}

Podemos considerar, de forma simplificada, que a questão dos gêneros não literários foi, ou é, abordada de diversas maneiras:

- Descrevendo as características formais dos textos e reunindo as marcas as mais recorrentes para concluir na determinação de um gênero textual. É o ponto de vista que define os gêneros a partir das 'recorrências lingüísticas'. Este ponto de vista se confronta com a natureza polissêmica do léxico e o fato de que muitas características dum gênero não são explícitas²;

- tentando definir os tipos de organização discursiva, tais como o 'narrativo', o 'argumentativo', o 'explicativo', o 'descritivo', etc. É o ponto de vista que define os gêneros a partir dos 'modos discursivos'. Mas, aqui, se confronta também com o problema da 'polidiscursividade';

- segundo as 'funções' de base da atividade linguageira. São as funções bem conhecidas de Jakobson (1963) ('emotiva', 'conativa', ‘fática', 'poética', 'referencial’ e 'metalingüística') ou, de maneira distinta, as de Halliday $(1973,1974)$, ('instrumental', 'interaccional', 'pessoal', 'heurística', 'imaginativa', 'interpessoal', etc.). É o ponto de vista que define os gêneros de maneira 'funcional', mas que levanta o problema de que um mesmo Gênero pode incluir varias funções:

- determinando as 'situações de comunicação' que resultam da maneira como uma sociedade estrutura, institucionalmente, a prática social em grandes setores de atividade como o 'político', o 'religioso', o ‘jurídico', o ‘científico', o ‘educativo', etc. É um ponto de vista socio-comunicacional que parte das condições sociais de produção e define os Gêneros a partir do seu ancoragem social. Dentro desta perspectiva, esta a 'natureza comunicacional' da troca verbal, segundo na linha de Bakhtin (1984): uma, natural, espontânea ('gêneros primeiros'), outra construída, institucionalizada ('gêneros segundos').

Esta rápida revisão das formas de abordar a noção de gênero não tem a pretensão de ser exaustiva. Ela nos (re)lembra, entretanto, a complexidade da questão. Ela serve, sobretudo, para mostrar que o que é levado em conta para definir esta noção evidência, tanto a 'ancoragem social' do discurso, quanto a sua 'natureza comunicacional', tanto às 'atividades linguageiras' construídas, quanto às 'características formais' dos textos produzidos. Logo, podemos nos perguntar se estes diferentes aspectos não estão ligados.

Vai ser meu ponto de partida, levantando a hipótese de que o ato de linguajem como toda prática social tende a regular as trocas verbais e a instaurar regularidades discursivas, como mostrou a etnometodologia com a descrição das ritualizações linguageiras. Ainda falta encon- 
trar o meio de articular o domínio de prática social com a atividade discursiva. A dificuldade vem do fato que estes domínios de prática são extensivos demais e englobantes para que se possa marcar regularidades discursivas. A proposição que vai se seguir consiste precisamente em estruturar o domínio de prática social em domínio de comunicação.

\section{Proposta 1: Esquema do funcionamiento do ato de fala}

Diremos, em seguida, que uma análise dos gêneros deve se apoiar em uma teoria do fato linguageiro, dito de outra maneira, em uma teoria do discurso na qual possamos conhecer os 'princípios gerais' sobre os quais ela se funda e os 'mecanismos' que os colocam em funcionamento. Toda teoria do discurso implica, assim, que sejam determinados diferentes níveis de organização do fato linguageiro. Já expus, aqui e ali, os aspectos de uma teoria psicosóciocomunicativa (que chamo de 'semiodiscursiva') na qual me inscrevo. Me deterei, desse modo, aqui, somente nos aspectos que me parecem mais pertinentes para explicar minha posição sobre a questão dos gêneros:

- Todo ato de linguagem se realiza numa 'situação de comunicação' normatizada. A situação de comunicação ê o que determina o espaço da troca linguajeira, e suas condições de produção, trazendo limitações no seu processo de encenação. Assim, a situação de comunicação funda a 'legitimidade' dos sujeitos falantes constituindo o que eu chamo de 'contrato de comunicação’.

- Esta situação-contrato de comunicação da 'instruções discursivas' ao sujeito falante para realizar seu ato de fala. Se ele quer ser compreendido por seu interlocutor, deve respeitar essas instruções.

- Mas o contrato e as suas instruções não sendo o todo do ato de linguagem, é ecessário ao sujeito falante usar de estratégias discursivas para ser crido e para captar seu interlocutor ('credibilidade’ e 'captação'). Aqui não tratarei a questão da estratégias. Somente a questão da situação-contrato e de suas instruções, porque para mim ê o que funda os Gêneros.

Assim vemos que o mecanismo do funcionamento do ato de fala é duplo. Ele compreende por um lado, aquilo que estrutura o domínio de prática em domínio de comunicação, a saber, um conjunto de 'situações de comunicação', e por outro lado, aquilo que ordena a 'discursivização' a saber, a maneira de configurar formalmente o discurso com um conjunto de procedimentos semiodiscursivos.

A ‘situação de comunicação’ é o lugar onde se instituem as instruções que determinam a expectativa da troca, estas instruções provenientes ao mesmo tempo da 'identidade' dos parceiros 
e do lugar que eles ocupam na troca, da 'finalidade' que os religa em termos de finalidade, do 'propósito' que pode ser convocado e das 'circunstâncias materiais nas quais a troca se realiza. Quando um conjunto de situações partilham as mesmas características, mesmo se algumas outras são diferentes, isso quer dizer que elas se encontram em um mesmo domínio de comunicação (por exemplo, as situações de comício parlamentario, de campanha eleitoral, de declaração televisiva de um ator político fazem parte do domínio de comunicação política). Destes componentes, me deterei mais particularmente, aqui, no da finalidade, porque é ele que, selecionando um tipo de finalidade, determina a orientação discursiva da comunicação. É evidente, entretanto, que não podemos dissociar estes componentes uns dos outros, e que é conjuntamente que eles contribuem para definir a expectativa da comunicação. Este nível é metodologicamente aquele pelo qual deve começar a análise dos discursos.

A 'discursivização' é o lugar onde se instituem, sob o efeito das instruções da situação, as diferentes 'maneiras de dizer' mais ou menos codificadas. Este lugar é, então, também ele, um lugar de instruções, mas convém distinguir aqui as instruções discursivas das instruções formais. Esta distinção se faz necessária para resolver o problema assinalado mais acima, resultante do fato que vários textos pudessem dar a impressão de pertencer a uma mesma classe de textos, enquanto que algumas de suas formas são distintas. 0 que se ressalta das instruções discursivas é da ordem de atividades de ordenamento do discurso (os modos discursivos) sem que possa ser determinada de maneira automática a forma exata do produto final. 0 que se ressalta das instruções formais, em compensação, corresponde a um emprego obrigatório das maneiras de dizer que encontramos necessariamente em todo texto pertencente à mesma situação.

Para ilustrar o valor explicativo destes níveis, poderemos citar o caso dos títulos de imprensa. Estes se inscrevem em uma situação de comunicação jornalística que se inscreve, ela própria, no domínio de comunicação midiática em nome de sua finalidade que seleciona uma finalidade de 'informação'. Estes dados situacionais demandam uma restrição discursiva de 'anúncio' das notícias que demanda por sua vez esta restrição formal de 'titulação'. Vemos, assim, que poderíamos falar de gêneros em cada um destes diferentes níveis: o gênero 'informação' determinado pelo domínio midiático, o gênero 'jornalístico determinado pela situação, o gênero 'anúncio' determinado pela restrição discursiva, o gênero ‘título’ determinado pela restrição formal.

\section{Proposta 2: Como determinar a situação de comunicação}

A 'situação de comunicação' se estrutura segundo a 'finalidade' do ato de fala, a 'identidade' dos parceiros e do lugar que eles ocupam na troca, as 'circunstâncias materiais' nas quais a troca se realiza. 
Destes componentes, me deterei mais particularmente, aqui, no da finalidade, porque é ele que, selecionando um tipo de finalidade comunicativa, determina a orientação discursiva da comunicação, e ao mesmo tempo a identidade discursiva dos interlocutores. Mas ê evidente que não se pode dissociar estes componentes uns dos outros.

A 'finalidade' corresponde a uma intencionalidade psico-sócio-discursiva que determina a expectativa do ato de linguagem do sujeito falante e por conseguinte da própria troca linguageira. A finalidade deve ser considerada do ponto de vista da instância de produção que tem em perspectiva um sujeito destinatário ideal, mas evidentemente ela deve ser reconhecida como tal pela instância de recepção ${ }^{3}$; é necessário que o locutor e o interlocutor possam recorrer a ela. A finalidade corresponde, assim, a uma atitude enunciativa de base que encontraríamos em um grande 'corpus' de atos comunicativos reagrupados em nome de sua orientação pragmática, mas além de sua ancoragem situacional.

Se pode definir os tipos de finalidade por um duplo critério: a intenção pragmática do 'Eu' em relação com a posição que ele ocupa como enunciador na relação de força que o liga ao 'Tu'; a posição que da mesma forma ' $T u$ ' deve 4 ocupar. Sem entrar em detalhes, descreveremos, aqui, três das principais finalidades ${ }^{5}$; porque são elas que vão me servir para a descrição dos discursos propagandísticos:

- a finalidade de 'prescrição': 'Eu' quer 'mandar fazer', e ele tem autoridade de poder sancionar; 'Tu' se encontra, então, em posição de 'dever fazer'.

- a finalidade de 'informação': ‘Eu' quer 'fazer saber', e ele está legitimado em sua posição de saber; 'Tu' se encontra na posição de dever saber’ ${ }^{6}$ alguma coisa sobre a existência dos fatos, ou sobre o porque ou o como de seu surgimento.

- a finalidade de 'incitação': ‘Eu' quer 'mandar fazer', mas, não estando em posição de autoridade, não pode não pode obrigar o 'Tu' a fazer; ele deve, então 'fazer acreditar' (por persuasão ou sedução) ao 'Tu' que ele será o beneficiário de seu próprio ato; 'Tu' está, então, em posição de 'dever acreditar’ que se ele age, é para o seu bem.

Para evitar qualquer mal entendido, convém precisar, aqui, o que essas finalidades não são. Elas não constituem esquematizações abstratas de um texto, visto que elas se situam bem a frente deste; é uma intenção discursiva que não prejulga aquilo que deve ser a organização textual.

Elas não correspondem a 'atos de fala'7, no sentido da pragmática, mesmo se elas partilham com eles o fato de que se trata de uma co-enunciação intencional que é marcada pelo efeito que ela é suscetível produzir. Os atos de fala são unidades mais finas que se situam em um nível mais engajado na realização discursiva, o enunciado. De fato, um ato como o de 'prometer', 
segundo o contexto, poderá corresponder a uma finalidade de prescrição, de incitação ou de informação.

Estas finalidades também não correspondem às ‘funções da linguagem' tais como definidas por Jakobson (1963), visto que mesmo vendo afinidades entre algumas destas funções e as finalidades, estas são, neste momento, bem mais distintivas que aquelas. A função conativa, por exemplo, pode se inserir em uma finalidade prescritiva, solicitativa ou incitativa. Além disso, as funções referencial, metalingüística ou poética deveriam ser antes consideradas como funções internas à linguagem do que como finalidades comunicativas intencionais.

Enfim, estas finalidades não podem constituir um princípio de tipologização dos textos, visto que elas se encontram bem a frente da configuração textual e que elas não permitem prejulgar o que esta será. Juntar todos os textos que correspondem a uma finalidade de informação conduziria a constituir um conjunto heterogêneo do ponto de vista de sua situação de emprego. Entretanto, estas finalidades são necessárias, como veremos agora, para definir estas situações.

Cada situação de comunicação seleciona uma ou várias finalidades dentre as quais geralmente uma (às vezes duas) é dominante ${ }^{8}$. Assim, a situação de comunicação midiática pode convocar várias finalidades: de 'instrução' (em suas rubricas de conselhos), de 'incitação' (em seus títulos dramatizantes), de 'demonstração' (quando ela dá a palavra aos espertos). Mas ela o faz sob a cobertura da finalidade dominante de informação (quer dizer daquela que determina a expectativa do contrato de comunicação). Mais exatamente, ela o faz sob uma finalidade dominante dupla: de 'informação', para responder à exigência democrática que quer que a opinião pública seja esclarecida sobre os acontecimentos que se produzem no espaço público; de 'incitação', para responder à exigência de concorrência comercial que quer que este discurso se enderece ao maior número e, desse modo, procure captá-lo (Charaudeau, 1995).

A situação de comunicação é, assim, o que determina, através das características de seus componentes, as condições de produção e de reconhecimento dos atos de comunicação, condições de enunciação sob seu aspecto externo. É por isso que podemos falar de 'contrato de comunicação': todo domínio de comunicação propõe a seus parceiros um certo número de condições que definem a expectativa da troca comunicativa, que sem o seu reconhecimento não haveria possibilidade de intercompreensão. As situações particulares seriam, então, consideradas como variantes (ou sub-contratos) de um contrato global. 


\section{Do contrato às instruções discursivas}

As instruções situacionais do ato de comunicação devem ser consideradas como dados externos, tendo por finalidade construir o discurso; elas respondem à questão do 'estamos aqui para dizer o quê?' e, fazendo isso, elas encontram seu correspondente em um 'como dizer?' A ligação entre os dados externos e a construção discursiva é de causalidade, mas ela não se estabelece em uma correspondência termo a termo. Os dados determinam o que deve ser o quadro do tratamento linguageiro no qual eles vão se ordenar.

Assim, observaremos que os dados da finalidade determinam uma certa escolha dos 'modos enoncivos' (descritivo, narrativo, argumentativo) ${ }^{9}$ que deve empregar o sujeito falante; os dados da identidade dos parceiros determinam certos 'modos enunciativos' (alocutivo, elocutivo, delocutivo) nos quais ele deve se engajar; os dados do propósito determinam certos 'modos de tematização', quer dizer a organização dos temas e sub-temas a serem tratados; os dados das circunstâncias materiais determinam certos 'modos de semiologização', quer dizer a organização textual (verbal e/ou visual) do ato de comunicação. As instruções discursivas não correspondem a uma obrigação de emprego desta ou daquela forma textual, mas a um conjunto de comportamentos discursivos possíveis entre os quais o sujeito comunicante escolhe aqueles que são suscetíveis de satisfazer às condições dos dados externos.

Para ilustrar a ordem das instruções discursivas, retomarei, simplificando, aquelas que já descrevi a propósito do contrato midiático (Charaudeau, 2006). As finalidades de informação e de incitação que o caracterizam determinam um quadro de tratamento no qual a instância midiática é levada a: tomar conhecimento do acontecimento para transformá-lo em notícia ('acontecimento narrado'), utilizando procedimentos descritivos e narrativos, às vezes objetivantes (credibilidade), às vezes dramatizantes (captação); explicar o acontecimento ('análise e comentário'), utilizando procedimentos argumentativos; produzir o acontecimento ('acontecimento provocado'), utilizando procedimentos de interação (debates, conversas, entrevistas).

A situação de comunicação é, assim, o que determina, através das características de seus 'componentes', e das 'instruções discursivas', as condições de produção e de reconhecimento dos atos de comunicação. É por isso que podemos falar de 'contrato de comunicação': sem o seu reconhecimento não haveria possibilidade de intercompreensão.

\section{De alguns contratos de discursos propagandísticos}

No quadro deste artigo não tenho a possibilidade de ilustrar todos os casos de relação entre os dados situacionais, as instruções discursivas e as realizações formais. Terminarei dando so- 
mente três casos de contrato de comunicação de discursos que pertencem ao que se poderia chamar de discurso propagandístico.

O discurso propagandístico se caracteriza por sua finalidade de incitação, que como diz no inicio se define da maneira seguinte: o 'Eu' quer 'fazer fazer' ('fazer pensar'); o 'Eu' esta em posição de 'não autoridade' (para impor um fazer), e então deve procurar um modo de 'fazer crer' (no sentido de que deve fazer que o outro chegue a crer); o 'Tu' esta em posição de 'dever crer'. Todas essas características constituem parte dos contratos dos discursos publicitários, promocional e político.

Mas, cada um desses discursos tens especificidades próprias que dependem do 'tipo de legitimidade' exercida pelo sujeito influenciador; da 'natureza do objeto de fala' que constitui o 'fazer crer’ e o ‘dever crer’; do ‘lugar designado’ ao sujeito destinatário.

\subsection{O discurso publicitário: Contrato de 'semi-engano'}

O discurso publicitário se desenvolve num dispositivo triangular entre uma instância 'publicista', uma instância 'concorrência' (a outra marca de produto), uma instância 'público'.

- A 'instância publicista' tira sua legitimidade de seu posicionamento numa economia de mercado: o direito de louvar as qualidades de um produto em face de seus concorrentes. Isso faz que a retórica do discurso publicitário seja 'superlativa' (e não comparativa como a do discurso político).

- O ‘objeto de discurso’ é um benefício individual no qual o produto, ‘bem de consumo’ (e não 'bem de sociedade' como no político), é o auxiliar.

- A 'instância 'público' é ao mesmo tempo um 'consumidor comprador potencial' e um 'consumidor efetivo da publicidade’. Esta instancia ê distinta da instância cidadã.

Como 'consumidor comprador' ele é destinado a 'dever crer' que tem uma carência e ele não pode desejar mais nada do que ser o agente de uma busca que cobrirá sua carência, sendo o objeto dessa busca o benefício louvado (é uma idealidade individual e não uma idealidade social). Por exemplo, a publicidade sobre uma creme anti-rugas apela ao sonho de eterna juventude. Como 'consumidor da publicidade', ele é levado a reconhecer a habilidade, a astúcia, o êxito da mesma publicidade. É como um apelo à conivência. Seu 'dever crer' é aqui suspenso em proveito de um 'dever apreciar'.

A 'idealidade individual', 'a retórica superlativa', o 'apelo à conivência' fazem com que o discurso publicitário, se manipulador, se insere num 'contrato de semi-engano', porque o publico 
consumidor sabe perfeitamente que o discurso publicitário propõe um sonho que não se pode conseguir, mas ele mesmo gosta de sonhar como si fora verdade.

\subsection{0 discurso promocional: Contrato de 'benefício social'}

O discurso promocional não louva uma marca, mas visa à prevenção ou a dissuasão de certos comportamentos sociais (ajuda aos deficientes, utilização de preservativos, contra o consumo exagerado de fumo e álcool, etc.).

- A 'instância promotor' tira sua legitimidade da posição de 'saber' (suposta) e de uma postura de 'moral social'. Não se trata de se situar em concorrência sobre um mercado de bens de consumo, mas como responsável de uma idealidade social. Ela é uma 'conselheira' e uma 'benfeitora'.

- 0 'objeto de discurso' é um benefício coletivo de reparação de uma desordem social que participa de uma idealidade ética (o ‘bem-estar’ não é individual).

- A 'instância 'público' é civil, destinada moralmente a 'dever reconhecer-se' no comportamento estigmatizado e a 'dever querer' seguir um certo comportamento em nome de uma solidariedade social.

Na campanha promocional, a 'carência' não é uma ausência (como na publicidade), mas um tipo de comportamento existente que é estigmatizado como mau (beber, fumar, engordar, dirigir em velocidade). A carência é então nesse caso um existente mau ('você fuma, é perigoso para a saúde'), enquanto que na publicidade é uma 'ausência de um potencialmente bom' ('você não tem sedução suficiente, mas pode ter').

Assim, a carência, nas campanhas de promoção representa sempre uma ameaça (graves consequiências), e o indivíduo destinatário não pode desempenhar o papel de inocente. Deve-se sentir obrigado a reconhecer que seu estado, ou o dos outros, representa um perigo social, e que ele deve fazer-se violência para aceitar uma busca não desejada.

Não há assim escapatória possível para ele, porque ele não pode contentar-se em ser o que é. É Aqui, uma manipulação legítima em nome de uma busca ética, a ética de responsabilidade como diz Max Weber. Por isso se pode dizer que o contrato promocional é de 'beneficio social'. 


\subsection{O discurso político: Contrato de 'benefício cidadão'}

A atividade de persuasão e de sedução é constitutiva do discurso política, visto que, em democracia, é preciso conquistar o poder ou o gerir com assentimento popular. Não somente a palavra política se dirige a um público, mas é preciso tentar atingir o maior número possível que constitui um auditório heterogêneo cujo denominador comum de compreensão é muito reduzido. É preciso então partir do princípio que no domínio político, 'nem tudo pode ser dito'.

- A ‘instância político’ tira sua legitimidade, no regime democrático, do processo de representação popular. 0 ator político investido de tal legitimidade é responsável do objetivo político, para o qual foi elegido. Alem disso deve se situar em concorrência com um adversário que tem os mesmos objetivos. Neste caso o discurso dele vai ser de 'promessa'.

- O ‘objeto de discurso' é de uma 'idealidade social’ que busca o bem-estar do cidadão, em 'contra do' desordem social e político existente.

- A 'instância “público': é cidadã, o seja destinada moralmente a 'dever aceitar' e 'reconhecer' a legitimidade do ator político elegido, deve se aderir a o projeto político pelo qual votou. Mas ao mesmo tempo tem 'direito a controlar' a ação política do responsável do projeto (pelo menos assim era na democracia ateniana, e pode-se seguir considerando que deve ser o ideal democrático). Neste sentido o contrato de do discurso político é, idealmente, de 'beneficio cidadã'.

Cada um desses três contratos dão instruções discursivas próprias ao sujeito falante, o qual deve a respeitar para que seja compreendido, e depois, em função disso pode eleger suas estratégias par persuadir o seduzir melhor o destinatário.

\section{CONCLUSÃO}

Respeito a problemática que descrevei ao início, vê-se que a noção de 'gênero' pode ser definida desde vários pontos de vista: alguns mais externos (da ancoragem social), outros mais lingüísticos (até das marcas formais). Mas eu me mantenho nesta terminologia de três níveis que tem o mérito de ser clara:

- o nível do 'contrato global' de comunicação com suas variantes, os dados situacionais que dão instruções discursivas específicas ao sujeito falante;

- o nível ‘discursivo’ em seus distintos modos de organização, em função dos dados situacionais e de suas instruções; 
- as 'formas textuais' com as marcas gramaticais e lexicais, cujas recorrências formais testemunham das regularidades da configuração textual que correspondem as instruções discursivas.

Poderíamos, então, a respeito destas categorias, falar de 'gênero situacional' para se referir às condições do contrato ${ }^{10}$, falar de 'sub-gêneros' como se fala de 'sub-contratos' que são as variantes encaixadas em um contrato global. Desde então, o narrativo, o descritivo, o explicativo e o argumentativo não seriam, nesta perspectiva gêneros porque cada uma dessas categorias da atividade discursiva reuniria textos pertencentes a situações diferentes e logo não poderia constituir um critério de classificação que correspondesse aos domínios da prática comunicativa. Do mesmo modo, uma recorrência de marcas formais, por mais forte que ela seja, não pode sozinha, ser significativa de um tipo de texto (salvo no caso de textos codificados, como os formulários administrativos), visto a circulação dessas marcas entre diversos textos. Elas não serão consideradas senão como traços daquilo que as instruções discursivas e situacionais ordenam.

Cada um destes princípios de classificação é legítimo e pode ser útil segundo o objetivo de análise que se propõe seguir. A posição aqui defendida é que uma definição dos gêneros de discurso passa pela articulação entre esses três níveis e a correlação (e não em implicação sucessiva) dos dados que cada um desses níveis propõe. Nessa perspectiva, é difícil definir o gênero como um protótipo ou como uma esquematização abstrata, visto que há componentes demais de ordem diferente que intervém para sua composição, a menos que aconteça de um dia se construir um modelo cognitivo que chegue a integrá-los e axiomatizá-los.

Enfim, no domínio da didática das línguas, diria que a questão dos gêneros, vista desta forma, deve permitir, de uma maneira melhor, tornar o aprendiz consciente da maneira cuja a escolha das formas linguageiras está ligada à percepção que temos das constantes situacionais, seja para respeitá-las ou para jogar com elas com fins estratégicos.

\section{REFERÊNCIAS BIBLIOGRÁFICAS}

Adam, J. (1992). Les textes: Types et prototypes. Récit, description, argumentation, explication et dialogue. Paris: Nathan Université.

Bakhtin, M. (1984). Esthétique de la création verbale. Paris: Gallimard.

Charaudeau, P. (1995). Une analyse sémiolinguistique du discours. Revue Langages, 117, 96111. 
Charaudeau, P. (2004a). Visadas discursivas, gêneros situacionais e construção textual. En I. L. Machado \& R. de Mello (Eds.), Gêneros reflexões em análise do discurso (pp. 13-41). Nad/Fale-UFMG, Belo Horizonte.

Charaudeau, P. (2004b). Dicionário de Análise do Discurso. Contexto: São Paulo.

Charaudeau, P. (2006). Discurso das Mídias. Contexto: São Paulo.

Charaudeau, P. (2009). Linguagem e discurso. Modos de organização. Contexto: São Paulo.

Halliday, M. A. K. (1973). The functional basis of language. En D. Bernstein (Ed.), Class, codes and control (pp. 22-47). London: Routledge and Kegan Paul.

Halliday, M. A. K. (1974). Dialogue with H. Parret. En H. Parret (Ed.), Discussing language (pp. 173-195). La Haye: Mouton.

Jakobson, R. (1963). Essais de linguistique générale. Paris: Minuit.

Lês Carnets du Cediscor (1992). Un Lieu d'inscription de la didacticité. Presses de la Sorbonne Nouvelle, 1.

\section{NOTAS}

1 Havendo escrito vários artigos sobre esta questão, retomarei aqui alguns deles (Charaudeau, 2004a) para me concentrar num caso particular: 'os gêneros propagandísticos'.

2 Les Carnets du Cediscor (1992).

3 Adam (1992).

4 Para que haja intercompreensão, o sujeito interpretante, que se encontra na instância de recepção, deve pelo menos reconhecer a finalidade.

5 A palavra deve, aqui, não tem o valor de uma norma moral. Ele assinala um horizonte de expectativa, o lugar (posição e ação) que é atribuído de antemão ao 'tu' se ele quer entrar na parceria do ato comunicativo.

6 Para as outras finalidades, veja Charaudeau (2004b).

7 Quer dizer que ele não pode não querer saber, 'dever saber' que é freqüentemente justificado ‘a posteriori'.

8 Às vezes, dizemos 'atos de linguagem', mas empregando eu mesmo esta expressão em um sentido mais amplo de ato comunicativo, prefiro falar de 'ato de fala' quando se trata do sentido que lhe dá a pragmática.

9 Retomamos, aqui, a idéia de dominância sugerida por Jakobson, a propósito das funções da linguagem.

10 O modo 'descritivo' serve para descrever um estado dos seres e do mundo; o modo 'narrativo' serve para descrever as ações humanas, ou tidas como tais, que se originam em um projeto de busca; o modo 'argumentativo' serve para descrever as lógicas que se decompõem elas próprias 
em 'explicativas' quando a verdade já é estabelecida e que é preciso explicar o como dos fenômenos, e em 'demonstrativos' quando se trata de estabelecer e de provar a verdade (Charaudeau, 2009). Por esta última categoria, não confundi-la com a visada, mesmo que ela seja objeto de uma mesma definição. Aqui, trata-se de um procedimento, enquanto que para a visada, trata-se de uma intenção pragmática.

11 Ou de gênero textual se nos referirmos ao conjunto dos textos reunidos em nome de seu pertencimento a um mesmo contrato. 